\title{
An electrocardiographic and echocardiographic assessment of football athletes
}

\begin{abstract}
Objectives: Exercise training causes physiologic and morphologic cardiac adaptation including sinus bradycardia and increased LV mass. The aim of this study was to define the electrocardiographic and echocardiographic findings in football male players which could occur as a response to regular physical training.
\end{abstract}

Methods: The present cross-sectional study was conducted on 60 male football players who were recruited during pre-competition medical assessment. Standard 12 lead resting electrocardiography and resting echocardiography were performed for all participants. 20 sex- and age-matched healthy persons were used as a control group.

Results: The mean age of athletes was $25.7 \pm 4.47$ and the mean body surface area (BSA) was $1.865 \pm 0.1 \mathrm{~m} 2$. Athletes had significant lower resting heart rate in comparison with control participants $(56.5 \pm 10$ versus $63.5 \pm 7.3$, $\mathrm{p}=0.002)$. $27(45 \%)$ athletes demonstrated sinus bradycardia. Twenty three (38.3\%) athletes demonstrated ST-segment elevation predominantly in anterior leads (V1-V3). The frequency of ST elevation among athletes was significantly higher in comparison with control participants $(p=<0.001)$. LV mass index were increased in athletes in comparison with control participants $(108 \pm 14$ versus $98.6 \pm 13.7 \mathrm{~g} / \mathrm{m} 2, \mathrm{p}=<0.05)$. In comparison with control subjects, athletes had higher trans-mitral $\mathrm{E}$ velocities $(75 \pm 13$ versus $68.4 \pm 11$ $\mathrm{cm} / \mathrm{s}, \mathrm{p}=<0.05)$, lower A velocities $(39.7 \pm 6.8$ versus $44 \pm 7.6 \mathrm{~cm} / \mathrm{s}, \mathrm{p}=<0.05)$, higher E/A ratio $(1.9 \pm 0.43$ versus $1.6 \pm 0.22 \mathrm{~cm} / \mathrm{s}, \mathrm{p}=<0.001)$, and higher tissue doppler early filling $\mathrm{e}^{\prime}$ velocities $(14 \pm 1.9$ versus $12.8 \pm 1.4 \mathrm{~cm} / \mathrm{s}, \mathrm{p}=<0.05)$.

Conclusion: In comparison with untrained participants, football athletes had lower resting heart rate, more frequent ST-segment elevation and greater LV mass and augmented LV filling. The systolic functions of LV remain within normal values.

Keywords: athletes, football players, IV mass
Volume 12 Issue I - 2019

Mohamed Yahia

Department of Cardiology, Faculty of Medicine, University of Menoufia, Egypt

Correspondence: Mohamed Yahia, Department of Cardiology, Faculty of Medicine, University of Menoufia, Egypt, Tel 00201005362162,Email m_yahia2000@yahoo.com

Received: January 07, 2019 | Published: January 21, 2019

\section{Introduction}

Electrocardiographic changes which are frequently seen in athletes include LV hypertrophy on voltage criteria, sinus bradycardia, prolonged PR interval, mobitz type 1 atrioventricular heart block and repolarization changes. ${ }^{1,2}$ These changes may mimic cardiac disease. Assessment by echocardiography differentiates between an athletic heart and a pathologic heart. The aim of this study was to define the electrocardiographic and echocardiographic findings in football male players which could occur as a response to regular physical training.

\section{Materials and methods}

\section{Study population}

Sixty male football players were involved in this cross sectional study. Participants were recruited during pre-competition medical assessment in 2016 in Saudi Arabia. A twenty age and sex matched healthy participants were used as a control group. The study excluded athletes in whom any cardiac diseases were detected during screening. The study was approved by our institution's local ethics committee. Written informed consent was obtained from all participants before their involvement. Standard 12-lead resting electrocardiography GE MAC 5500 HD electrocardiography machine was used to get a 12-lead resting ECG in the supine position. The paper speed was adjusted with speed of $25 \mathrm{~mm} / \mathrm{sec}$ and a calibration of $10 \mathrm{~mm} / \mathrm{mv}$.
Heart rate, cardiac axis, QRS voltage and duration, PR interval, QT interval, heart-rate-corrected QT interval was calculated according to Bazett's formula, ${ }^{3} \mathrm{ST}$ segment and T wave were analyzed. STsegment elevation was defined as J-point elevation of at least $0.1 \mathrm{mV}$ in 2 contiguous leads. LV hypertrophy was defined according to the Sokolow-Lyon voltage criteria ${ }^{4}$ and the Romhilt-Estes score, a score of $\geq 5$ indicating LV hypertrophy. ${ }^{5}$

\section{Two dimensional transthoracic echocardiogram}

Two dimensional transthoracic echocardiogram was performed using a VIVID E9 echocardiogram (GE Healthcare, Chicago, USA) with a transducer of $3.5-\mathrm{mHz}$ phased-array. The average of three heart beats was used. Standard M-mode measurements were recorded from parasternal and apical views. The LV ejection fraction (EF) was estimated using the biplane method of disks (modified Simpson's rule) and the LV mass was calculated using the Deveraux formula. ${ }^{6}$ The LV mass index was calculated by dividing LV mass by BSA. Increased LV mass was diagnosed with value more $115 \mathrm{~g} / \mathrm{m} 2$. The recommendations of the American Society of Echocardiography were applied when recording all variables. ${ }^{7}$ The velocities of early (E) and late (A) diastolic transmitral flow, the E/A ratio and deceleration time of the E-wave were measured. Pulsed-wave Tissue Doppler Imaging (TDI) was performed on apical images. Peak systolic velocity (S'), peak early diastolic velocity (e') was recorded. Pulsed Doppler and TDI data were combined to calculate the E/e' ratio. ${ }^{8}$ 


\section{Statistical analysis}

Categorical data were presented as numbers and percentages and quantitative data were expressed as mean \pm standard deviation. Differences between control and athletes were analyzed by the 2 -tailed student $t$ test for unpaired observations. Chi square tests (X2) were used to analyze categorical variables. $\mathrm{P}$ value less than $<0.05$ was considered significant.

\section{Results}

Table 1 demonstrates characteristics and ECG findings of the studied players. The mean age of athletes was $25.7 \pm 4.47$, and the mean BSA was $1.865 \pm 0.1 \mathrm{~m} 2$. Two (3.4\%) players had prolonged PR interval, and 27 (45\%) athletes demonstrated sinus bradycardia. None of the players demonstrated 2nd or 3rd degree atrioventricular block. Athletes had significant lower resting heart rate in comparison with control participants $(56.5 \pm 10$ versus $63.5 \pm 7.3, \mathrm{p}=0.002)$. Twenty three $(38.3 \%)$ athletes demonstrated ST-segment elevation predominantly in anterior leads (V1-V3). The frequency of ST elevation among athletes was significantly higher in comparison with control participants $(\mathrm{p}=<0.001)$. ST depression and $\mathrm{T}$ wave changes were present in $8(13.3 \%)$ players in inferolateral leads. One $(1.7 \%)$ player had left axis deviation. Twenty one $(35 \%)$ players had the Sokolow-Lyon voltage criteria of LV hypertrophy and 9(15\%) had LV hypertrophy by the Romhilt-Estes score. There were non-significant statistical differences between athletes and control participants in regard BSA, PR intervals, QRS duration, and QTc interval.

Table I Characteristic and electrocardiographic findings of football players

\begin{tabular}{ll}
\hline & Athletes (N=60) \\
\hline Age (ys) & $25.9 \pm 4.6$ \\
BSA (m2) & $1.85 \pm 0.1$ \\
Resting HR (bpm) & $56.5 \pm 10$ \\
Sinus bradycardia (n. \%) & $27(45 \%)$ \\
PR interval (ms) & $174 \pm 22.5$ \\
QRS duration (ms) & $96 \pm 9.5$ \\
QTc (ms) & $415 \pm 22$ \\
Left axis deviation (n. \%) & $\mathrm{I}(\mathrm{I} .7 \%)$ \\
LVH: Sokolow-Lyon criteria (n. \%) & $2 \mathrm{I}(35 \%)$ \\
LVH: Romhilt-Estes score (n. \%) & $9(15 \%)$ \\
ST elevation (n. \%) & $23(38.3 \%)$ \\
ST depression, T wave changes (n. \%) & $8(\mathrm{I} 3.3 \%)$ \\
Incomplete RBBB (n. \%) & $\mathrm{I}(\mathrm{I} .7 \%)$ \\
PR interval > 200 ms (n. \%) & $2(3.4 \%)$
\end{tabular}

BSA, body surface area; HR, heart rate; QTc, corrected QT interval; LVH, left ventricular hypertrophy; RBBB, right bundle branch block

Variables are represented by mean \pm standard deviation or number and percent

Conventional echocardiography was performed on all groups. LV septal wall thickness was increased in comparison with control subjects $(0.96 \pm 15$ versus $0.83 \pm 14, p=<0.05)$. LV internal dimensions were increased in athletes in comparison with control participants; however, this difference did not reach a significant value. LV mass index was above normal value for male in $13(21.6 \%)$ players. LV mass index were increased in athletes in comparison with control participants $(108 \pm 14$ versus $98.6 \pm 13.7 \mathrm{~g} / \mathrm{m} 2, \mathrm{p}=<0.05)$. LV EF was at normal values in both groups and none of studied participants showed depressed systolic function or segmental wall motion abnormalities (Table 2). In comparison with control subjects, trans-mitral E velocity increased in athletes $(75 \pm 13$ versus $68.4 \pm 11 \mathrm{~cm} / \mathrm{s}, \mathrm{p}=<0.05)$, A wave reduced in athletes $(39.7 \pm 6.8$ versus $44 \pm 7.6 \mathrm{~cm} / \mathrm{s}, \mathrm{p}=<0.05)$ and $\mathrm{E} / \mathrm{A}$ ratio increased in athletes $(1.9 \pm 0.43$ versus $1.6 \pm 0.22 \mathrm{~cm} / \mathrm{s}, \mathrm{p}=<0.001)$. Athletes showed higher septal $\mathrm{S}^{\prime}$ in comparison with control participants $(10.2 \pm 1.4$ versus $9.3 \pm 1.1 \mathrm{~cm} / \mathrm{s}, \mathrm{p}=<0.05)$. The average $\mathrm{e}^{\prime}$ wave was significantly increased in athletes in comparison with control participants $(14 \pm 1.9$ versus $12.8 \pm 1.4 \mathrm{~cm} / \mathrm{s}, \mathrm{p}=<0.05)$. There was none significant difference two groups in regard E/e' ratio (Table 3)

Table 2 Two dimensional echocardiographic findings of studied groups

\begin{tabular}{lll}
\hline & Control $(\mathbf{N}=\mathbf{2 0})$ & Athletes $(\mathbf{N}=6 \mathbf{0})$ \\
\hline IVSD $(\mathrm{cm})$ & $0.83 \pm 0.14$ & $0.96 \pm 0.15^{* *}$ \\
$\operatorname{LVEDD}(\mathrm{cm})$ & $5 \pm 0.37$ & $5.2 \pm 0.43$ \\
$\operatorname{LVESD}(\mathrm{cm})$ & $3.4 \pm 0.3$ & $3.3 \pm 0.32$ \\
$\operatorname{LVEDV}(\mathrm{ml})$ & $123 \pm 22$ & $124 \pm 21$ \\
$\operatorname{LVESV}(\mathrm{ml})$ & $47.4 \pm 10.5$ & $46.6 \pm 6.6$ \\
$\operatorname{LVMI}(\mathrm{g} / \mathrm{m} 2)$ & $98.6 \pm 13.7$ & $108 \pm 14.8^{*}$ \\
$\operatorname{LVEF} \%$ & $60.7 \pm 5.3$ & $61.6 \pm 6.3$
\end{tabular}

IVSD, interventricular septal thickness at end diastole; LVEDD, left ventricular end diastolic dimension; LVESD, left ventricular end systolic dimension; LVEDV, left ventricular end diastolic volume; LVESV, left ventricular end systolic volume; LVMI, left ventricular mass index; LVEF, left ventricular ejection fraction Variables are represented by mean \pm standard deviation, $* \mathrm{P}<0.05, * * \mathrm{P}<0.005$

Table 3 Pulsed wave and tissue Doppler echocardiographic findings of studied groups

\begin{tabular}{lll}
\hline & Control $(\mathbf{N}=20)$ & Athletes $(\mathbf{N}=60)$ \\
\hline E $(\mathrm{cm} / \mathrm{s})$ & $68.4 \pm 1 \mid$ & $75 \pm 13^{*}$ \\
A $(\mathrm{cm} / \mathrm{s})$ & $44 \pm 7.6$ & $39.7 \pm 6.8^{*}$ \\
E/A ratio & $1.6 \pm 0.22$ & $1.9 \pm 0.43^{*}$ \\
DT $(\mathrm{ms})$ & $170 \pm 31$ & $181 \pm 37$ \\
$\mathrm{~S}^{\prime}$ septal $(\mathrm{cm} / \mathrm{s})$ & $9.3 \pm 1.1$ & $10.2 \pm 1.4^{*}$ \\
$\mathrm{~S}^{\prime}$ lateral $(\mathrm{cm} / \mathrm{s})$ & $10.2 \pm 1.5$ & $10.3 \pm 1.8$ \\
$\mathrm{e}^{\prime}$ septal $(\mathrm{cm} / \mathrm{s})$ & $11.4 \pm 1.8$ & $11.8 \pm 2$ \\
$\mathrm{e}^{\prime}$ lateral $(\mathrm{cm} / \mathrm{s})$ & $14.2 \pm 2$ & $16.4 \pm 2.7^{*}$ \\
$\mathrm{e}^{\prime}$ average $(\mathrm{cm} / \mathrm{s})$ & $12.8 \pm 1.4$ & $14 \pm 1.9 *$ \\
E/e' ratio & $5.4 \pm 1.1$ & $5.2 \pm 0.8$ \\
\hline
\end{tabular}

$E$, early peak pulsed doppler velocity on mitral valve; $A$, late pulsed doppler velocity on mitral valve; $D T$, deceleration time; $\mathrm{S}^{\prime}$ septal, systolic tissue velocity of septal annulus; $\mathrm{S}^{\prime}$ lateral, systolic tissue velocity of lateral annulus; $\mathrm{e}^{\prime}$ septal, early tissue velocity of septal annulus; $\mathrm{e}^{\prime}$ lateral, early tissue velocity of lateral annulus; $\mathrm{e}^{\prime}$ average, average of septal and lateral early tissue velocities

Variables are represented by mean \pm standard deviation or number and percent. $* \mathrm{P}<0.05, * * \mathrm{P}<0.005$ 


\section{Discussion}

Exercise training causes physiologic and morphologic cardiac adaptation including sinus bradycardia, an increase in LV internal dimensions and increased LV mass. ${ }^{9}$ In the present study, athletes demonstrated lower heart rate than controls, and this often relates to an augmented vagal tone in well trained athletes. LV systolic functions were within normal limits or better in athletes in comparison with control participants. In addition, athletes had higher tissue Doppler mitral annular S' velocities than control participants. These results strength the concept of LV hypertrophy which is associated with exercise training has no pathologic consideration. ${ }^{10}$

ST elevation is one of electrocardiographic changes that is noted in athletes. The foremost writings on the subject define ST elevation as J-point elevation on the ECG of $\geq 0.1 \mathrm{mV}$ in two adjacent leads. In the present study, $38 \%$ of the participants showed ST elevation. ST elevation in athletes may occur as a consequence of physiological resetting of the balance between the sympathetic and parasympathetic tones, which regulates transmembrane ionic currents. ${ }^{11}$ In athletes, ST elevation seems to disappear when training declines and often changes with increasing heart rate, suggesting a mechanism that is vagally mediated or sensitive to heart rate. ${ }^{12}$ The findings of this study are in agreement with previous studies, which reported significant frequency of ST elevation in athletes ${ }^{13-14}$ Baek et al. ${ }^{15}$ found a significant relationship between the presence of ST elevation and increased vagal activity in patients without structural heart diseases. ${ }^{15}$ Biasco et al. ${ }^{16}$ found a significant relation between ST elevation and LV hypertrophy in athletes and suggested a role of exercise-induced hypertrophy as the basis for ST elevation. ${ }^{16}$ Noteworthy et al. ${ }^{17}$ who reported that ST elevation was not related to LV voltage criteria on ECG, suggesting that ST elevation reflect an electric phenomenon. In the present study, $35 \%$ of athletes had the Sokolow-Lyon voltage criteria of LV hypertrophy and 15\% had LV hypertrophy by the Romhilt-Estes score. LV mass index was above normal value for male in $13(21.6 \%)$ players. According to these findings, an isolated QRS voltage is inadequate to diagnose LV hypertrophy in athletes. Similar results were reported by Crouse et al. ${ }^{18} \mathrm{QRS}$ voltage should be associated with other ECG signs including left axis deviation, repolarization signs, atrial enlargement, or increased QRS width, to indicate LV hypertrophy, where, the athlete should get further assessment. ${ }^{19,20}$

In the present study, athletes demonstrated increased E/A ratio due to an increase of $\mathrm{E}$ velocity and decrease of a velocity. In addition, tissue Doppler $\mathrm{e}^{\prime}$ velocities were increased in athletes in comparison with control participants. Previous studies concerned with evaluation of LV diastolic function among athletes. Pluim et al. ${ }^{21}$ reported that the E/A was either normal or slightly, but not significantly, enhanced in athletes compared to controls. Kneffel et al. ${ }^{22}$ reported the enhanced $\mathrm{E} / \mathrm{A}$ in athletes as being related to a diminished resting heart rate. Likewise, Baldi et al. ${ }^{23}$ and Zoncu et al. ${ }^{24}$ reported increased e' tissue velocities in trained athletes compared to controls. Similarly, Poh et al. ${ }^{25}$ reported higher e' in elite speeds katers in response to intensive physical training. Vinereanu et al. ${ }^{26}$ reported enhancement of LV diastolic function in endurance-trained compared with strength trained athletes. The normal or increased values of indices of LV filling differentiate athletic heart from other pathologic hypertrophy likes hypertrophic cardiomyopathy.

\section{Conclusion}

In comparison with untrained participants, football athletes had lower resting heart rate, greater LV mass, more frequent ST-segment elevation and augmented LV filling. The systolic functions of LV remain within normal values.

\section{Funding}

This is no funding authority to declare.

\section{Acknowledgments}

The author would like to thank Dr. Anas Al-Dahshan, assistant professor of physiotherapy, College of Applied Medical Sciences, Dammam University for his support to finish this work.

\section{Conflicts of interest}

The authors declare that they have no conflicts of interest.

\section{References}

1. Uberoi A, Stein R, Perez MV, et al. Interpretation of the Electrocardiogram of Young Athletes. Circulation. 124(6):746-757.

2. Zehender P, Meinertz $\mathrm{T}$, Keul $\mathrm{J}$, et al. ECG variants and cardiac arrhythmias in athletes: clinical relevance and prognostic importance. Am Heart J. 1990;119(6):1378-1378.

3. Bazett HC. An analysis of the time relations of electrocardiograms. Heart. 1920;7:353-367.

4. Sokolow M, Lyon TP. The ventricular complex in left ventricular hypertrophy as obtained by unipolar precordial and limb leads. Am Heart J. 2001;6(4):343-368.

5. Romhilt DW, Estes EH. A point-score system for the ECG diagnosis of left ventricular hypertrophy. Am Heart J. 1986;75:752-758.

6. Devereux RB, Alonso DR, Lutas EM, et al. Echocardiographic assessment of left ventricular hypertrophy: Comparison to necropsy findings. Am J Cardiol. 1986;57(6):450-458.

7. Lang RM, Badano LP, Mor-Avi V, et al. Recommendations for Cardiac Chamber Quantification by Echocardiography in Adults: An Update from the American Society of Echocardiography and the European Association of Cardiovascular Imaging. J Am Soc Echocardiogr. 2015;28(1):1-39.

8. Nagueh SF, Smiseth OA, Appleton CP, et al. Recommendations for the Evaluation of Left Ventricular Diastolic Function by Echocardiography: An Update from the American Society of Echocardiography and the European Association of Cardiovascular Imaging. Eur Heart $J$ Cardiovasc Imaging. 2016;17(12):1321-1360.

9. Maron BJ. Structural features of the athlete heart as defined by echocardiography. J Am Coll Cardiol. 1986;7(1):190-203.

10. Pearson A, Schniff M, Labovitz A, et al. Left ventricular systolic and diastolic function and hypertrophy in weight lifters. Am J Cardiol. 1968;58(13):1254-1259.

11. Barbosa EC, Bomfim Ade S, Benchimol-Barbosa PR, et al. Ionic mechanisms and vectorial model of early repolarization pattern in the surface electrocardiogram of the athlete. Ann Noninvasive Electrocardiol. 2008;13(3):301-307.

12. Cappato R, Furlanello F, Giovinazzo V, et al. J wave, QRS slurring, and ST elevation in athletes with cardiac arrest in the absence of heart disease: marker of risk or innocent bystander? Circ Arrhythm Electrophysiol. 2010;3(4):305-311.

13. Perez M, Fonda H, Le VV, et al. Adding an electrocardiogram to the preparticipation examination in competitive athletes: a systematic review. Curr Probl Cardiol. 2009;34(12):586-662.

14. Rosso R, Kogan E, Belhassen B, et al. J-point elevation in survivors of primary ventricular fibrillation and matched control subjects. $J$ Am Coll Cardiol. 2008;52(15):1231-1238. 
15. Baek YS, Park SD, Lee MJ, et al. Relationship between J Waves and Vagal Activity in Patients Who Do Not Have Structural Heart Disease. Ann Noninvasive Electrocardiol. 2015;20(5):464-673.

16. Biasco L, Cristoforetti Y, Castagno D, et al. Clinical, electrocardiographic echocardiographic characteristics and long-term follow-up of elite soccer players with J-point elevation. Circ Arrhythm Electrophysiology. 2013;6(6):1178-1184.

17. Noseworthy, Rory Weiner, Jonathan Kim, et al. Early Repolarization Pattern in Competitive Athletes: clinical correlates and the effects of exercise training. Circ Arrhythm Electrophysiol. 2011;4(4):432-440.

18. Crouse SF, Meade T, Hansen BE, et al. Electrocardiograms of collegiate football athletes. Clin Cardiol. 2009;32(1):37-42.

19. Ashley EA, Raxwal VK, Froelicher VF. The prevalence and prognostic significance of electrocardiographic abnormalities. Curr Probl Cardiol. 2000;25(1):1-72.

20. Hsieh BP, Pham MX, Froelicher VF. Prognostic value of electrocardiographic criteria for left ventricular hypertrophy. Am Heart J. 2005;150(1):161-167.
21. Pluim BM, Zwinderman AH, van der Laarse A, et al. The athlete's heart. A meta-analysis of cardiac structure and function. Circulation. 2011;101(3):336-344.

22. Kneffel Z, Varga-Pinter B, Toth M, et al. Relationship between heart rate and E/A ratio in athletic and non-athletic males. Acta Physiologica Hung. 2011;98(3):284-293.

23. Baldi JC, McFarlane K, Oxenham HC, et al. Left ventricular diastolic filling and systolic function of young and older trained and untrained men. J Appl Physiol. 2003;95(6):2570-2575.

24. Zoncu S, Pelliccia A, Mercuro G. Assessment of regional systolic and diastolic wall motion velocities in highly trained athletes by pulsed wave Doppler tissue imaging. J Am Soc Echocardiogr. 2002;15(9):900-905.

25. Poh KK, Ton-Nu TT, Neilan TG, et al. Myocardial adaptation and efficiency in response to intensive physical training in elite speedskaters. Int J Cardiol. 2008;126(3):346-351.

26. Vinereanu D, Florescu N, Sculthorpe N, et al. Left ventricular longaxis diastolic function is augmented in the hearts of endurance-trained compared with strength trained athletes. Clin Sci. 2002;103(3):249-257. 